\title{
Efficacy of natural plant products, Azadirachta indica, Ocimum sanctum and Pongamia pinnata in the management of greater wax moth, Galleria mellonella $\mathbf{L}$. under laboratory conditions
}

\section{N. S. Surendra, M. Bhushanam and M. S. Reddy*}

Centre for Apiculture Studies, Department of Zoology, Bangalore University, Jnana Bharathi, Bangalore-560056, INDIA *Corresponding author. E-mail: jenureddy@yahoo.co.in

\begin{abstract}
Use of Natural plant products in the management of the greater wax moth, G. mellonella L. under laboratory conditions was carried out. The results revealed that the larval mortality of wax moth varied significantly with three different plant products concentrations. The mortality was high with seed extract of Neem (Azadirachta indica) and is ranging from $84.81 \pm 2.7$ to $93.65 \pm 3.25$ per cent at different concentrations. Tulasi (Ocimum sanctum) leaf extract of different concentrations showed moderate larval mortality for different instars ranging from $65.36 \pm$ 4.36 to $73.41 \pm 4.46$ percent. The corresponding mortality for Pongamia (Pongamia pinnata) seed extract was low $31.10 \pm 3.38$ to $52.1 \pm 19.85$. The effects of tulasi were moderate while pongamia caused the lowest mortality. Of the three plant products tested Neem performed better under all the experimental conditions.
\end{abstract}

Keywords: Galleria mellonella, Wax moth, Natural plant products, Larval mortality, Neem, Tulasi

\section{INTRODUCTION}

Galleria mellonella is a useful insect, because its larvae make excellent bait for fish. To the beekeeper, wax moth is one of the serious pests of the honey bee colonies which feeds on comb wax and causes economic loss to the beekeeping industry. Use of chemical insecticides such as sulphur, para dichloro benzene and calcium cyanide is harmful to bee population (Grout, 1946; Whitecomb, 1967). In this context use of plant products as insecticides is emerging as a major thrust area in controlling greater wax moth. Natural plant products possess insecticidal activity. The plants based insecticides being the natural plant products are safer and hence their use against pests has gained importance all over the world (Alkofahi et al., 1989; Hiremath, 1994). High toxic effects of botanicals on the larvae of $G$. mellonella have been reported (Bolchi, 1979; Eischen and Dietz, 1987). Very little information is available on the comparative efficacy of different plant products against the larval mortality of the greater wax moth, Galleria mellonella $L$ Hence, the present investigation was aimed to screen different plant products, Neem, Tulasi and Pongamia against larval moratality of greater wax moth, Galleria mellonella L.

\section{MATERIALS AND METHODS}

The stock of greater wax moth was maintained under laboratory conditions at $26 \pm 2{ }^{\circ} \mathrm{C}$ and $80 \pm 10 \%$ relative humidity $(\mathrm{RH})$. The following natural plant products were used at different concentrations $(0.20,0.40,0.60,0.80$ and
1.00 per cent) throughout the course of this work. The treatments were as follows: T1- Seed extract of Neem (Azadirachta indica A.Juss); T2 -Leaf extract of Tulasi (Ocimum sanctum); T3-Seed extract of Pongamia (Pongamia pinnata); T4-Water as control.

The extracts were prepared by rotary vacuum flash evaporation method (Hiremath, 1994). From the stock of G. mellonella the eggs were collected on the pieces of honeycomb and transferred to a separate plastic container of $5 \times 6 \mathrm{~cm}$ size. Hatched larvae of G. mellonella were released separately into four different plastic containers in groups of twenty with pieces of comb. The extracts were sprayed on first to last instar larvae of wax moth by using high-pressure plastic sprayer on every alternate day. Water is sprayed as control. Each treatment was replicated thrice. Treated larvae were kept separately to record mortality on every successive alternate days. The data was subjected to ANNOVA at Alpha $(\mathrm{P}<0.05)$ levels (Khan and Khanum, 1994).

\section{RESULTS AND DISCUSSION}

There was variation in the larval mortality with the different concentrations of plant products. Variations were observed between larval stages also. The Neem seed extract showed the highest mortality rate of $79.67 \pm 1.12$ to $86.31 \pm 0.01,80.67 \pm 0.69$ to $90.26 \pm 0.8,86.33$ \pm 0.96 to $93.67 \pm 1.15,87.21 \pm 10.89$ to $96.42 \pm 2.51$ and $90.21 \pm 2.30$ to $100 \pm 0.00$ per cent in different larval instars when used at different concentrations of $0.20,0.40,0.60$, 0.80 and 1.00 per cent respectively (Table 1 ). Whereas, seed extract of Pongamia showed the least mortality rate 
Table 1. Mean per cent larval mortality of greater wax moth, Galleria mellonella after application of Neem, Tulasi, Pongamia extracts.

\begin{tabular}{|c|c|c|c|c|c|c|c|c|}
\hline \multirow[b]{2}{*}{$\begin{array}{c}\text { Conc. } \\
(\%)\end{array}$} & \multicolumn{7}{|c|}{ Percent Mortality in different instars } & \multirow[b]{2}{*}{$\begin{array}{c}\text { Mean total \% } \\
\text { mortality } \\
\left(\text { mean }^{*} \pm \text { S.D }\right) \#\end{array}$} \\
\hline & $\begin{array}{c}\text { I } \\
\text { (mean* } \\
\pm \text { S.D)\# }\end{array}$ & $\begin{array}{c}\text { II } \\
(\text { mean* } \\
\pm \text { S.D)\# }\end{array}$ & $\begin{array}{c}\text { III } \\
(\text { mean* } \\
\pm \text { S.D)\# }\end{array}$ & $\begin{array}{c}\text { IV } \\
(\text { mean* } \\
\pm \text { S.D)\# }\end{array}$ & $\begin{array}{c}\mathrm{V} \\
(\mathrm{mean} * \\
\pm \text { S.D)\# }\end{array}$ & $\begin{array}{c}\text { VI } \\
(\text { mean* } \\
\pm \text { S.D)\# }\end{array}$ & $\begin{array}{c}\text { VII } \\
(\text { mean* } \\
\pm \text { S.D)\# }\end{array}$ & \\
\hline \multicolumn{9}{|c|}{ NEEM } \\
\hline 0.20 & $86.21 \pm 0.01$ & $86.31 \pm 0.01$ & $81.44 \pm 0.50$ & $82.94 \pm 0.45$ & $80.33 \pm 0.12$ & $81.21 \pm 1.11$ & $79.67 \pm 1.12$ & $82.67 \pm 2.7$ \\
\hline 0.40 & $88.98 \pm 1.70$ & $90.26 \pm 0.82$ & $88.24 \pm 1.15$ & $86.22 \pm 3.95$ & $85.24 \pm 0.02$ & $83.13 \pm 5.34$ & $80.67 \pm 0.69$ & $86.11 \pm 3.39$ \\
\hline 0.60 & $91.32 \pm 2.45$ & $93.67 \pm 1.15$ & $92.36 \pm 1.51$ & $89.34 \pm 1.52$ & $88.68 \pm 5.03$ & $87.56 \pm 4.10$ & $86.33 \pm 0.96$ & $89.89 \pm 2.65$ \\
\hline 0.80 & $92.11 \pm 4.45$ & $96.42 \pm 2.51$ & $94.72 \pm 3.03$ & $90.33 \pm 0.96$ & $92.67 \pm 1.04$ & $89.33 \pm 0.63$ & $87.21 \pm 10.89$ & $91.83 \pm 3.16$ \\
\hline 1.00 & $98.64 \pm 4.13$ & $99.31 \pm 0.28$ & $100 \pm 0.0$ & $97.25 \pm 0.88$ & $96.51 \pm 1.04$ & $96.76 \pm 3.18$ & $90.21 \pm 2.30$ & $96.95 \pm 3.25$ \\
\hline \multicolumn{9}{|c|}{ TULASI } \\
\hline 0.20 & $71.22 \pm 0.02$ & $69.64 \pm 0.56$ & $67.42 \pm 1.50$ & $65.72 \pm 1.19$ & $62.53 \pm 0.61$ & $61.41 \pm 0.62$ & $59.55 \pm 0.47$ & $65.36 \pm 4.36$ \\
\hline 0.40 & $72.32 \pm 0.85$ & $70.35 \pm 0.60$ & $69.54 \pm 0.39$ & $67.33 \pm 0.8$ & $64.22 \pm 1.05$ & $62.22 \pm 2.05$ & $60.33 \pm 0.09$ & $66.62 \pm 4.47$ \\
\hline 0.60 & $74.94 \pm 1.54$ & $71.54 \pm 1.06$ & $70.62 \pm 0.69$ & $69.42 \pm 0.54$ & $65.44 \pm 0.67$ & $64.00 \pm 0.0$ & $63.42 \pm 0.61$ & $68.48 \pm 4.31$ \\
\hline 0.80 & $76.22 \pm 0.19$ & $74.61 \pm 1.15$ & $71.23 \pm 0.06$ & $70.42 \pm 0.50$ & $66.62 \pm 1.43$ & $66.04 \pm 0.06$ & $65.35 \pm 0.56$ & $70.07 \pm 4.28$ \\
\hline 1.0 & $80.22 \pm 0.99$ & $78.24 \pm 1.00$ & $74.00 \pm 1$ & $73.21 \pm 1.04$ & $70.11 \pm 0.10$ & $69.42 \pm 0.60$ & $68.65 \pm 0.49$ & $73.41 \pm 4.46$ \\
\hline \multicolumn{9}{|c|}{ PONGAMIA } \\
\hline 0.20 & $35.24 \pm 0.89$ & $26.22 \pm 1.00$ & $28.92 \pm 1.38$ & $34.57 \pm 3.60$ & $28.12 \pm 0.96$ & $32.15 \pm 0.99$ & $32.17 \pm 1.05$ & $31.10 \pm 3.38$ \\
\hline 0.40 & $48.11 \pm 0.11$ & $28.41 \pm 0.01$ & $30.68 \pm 0.01$ & $45.36 \pm 0.02$ & $30.23 \pm 0.02$ & $38.25 \pm 0.01$ & $36.81 \pm 0.01$ & $36.84 \pm 7.68$ \\
\hline 0.60 & $64.45 \pm 0.01$ & $29.36 \pm 0.94$ & $31.71 \pm 0.51$ & $51.44 \pm 0.01$ & $34.26 \pm 0.06$ & $46.52 \pm 0.02$ & $38.42 \pm 0.01$ & $42.31 \pm 12.59$ \\
\hline 0.80 & $78.23 \pm 0.01$ & $31.42 \pm 0.01$ & $34.14 \pm 0.01$ & $56.21 \pm 0.01$ & $36.33 \pm 0.01$ & $49.67 \pm 0.02$ & $42.67 \pm 0.02$ & $46.95 \pm 16.37$ \\
\hline 1.0 & $89.79 \pm 0.02$ & $35.12 \pm 0.01$ & $36.31 \pm 0.01$ & $66.01 \pm 0.01$ & $38.74 \pm 0.02$ & $52.32 \pm 0.01$ & $46.26 \pm 0.01$ & $52.1 \pm 19.85$ \\
\hline \multicolumn{9}{|c|}{ CONTROL } \\
\hline ----- & 3.50 & 3.25 & 2.89 & 1.45 & 1.20 & 2.12 & 1.98 & \\
\hline
\end{tabular}

* Average of five replicates, 20 larvae per replicate; \# Values are significantly different $(\mathrm{P}<0.05)$; Neem: cd @ 5\% (2.281502); Tulasi: cd@ 5\%(0.629283); Pongamia : cd@ 5\%(0.475503)

of $26.22 \pm 1.00$ to $35.24 \pm 0.89,28.41 \pm 0.01$ to $48.11 \pm 0.11$, $29.36 \pm 0.94$ to $64.45 \pm 0.01,31.42 \pm 0.01$ to $78.23 \pm 0.01$, $35.12 \pm 0.01$ to $89.79 \pm 0.02$ per cent in different larval instars at different concentrations of $0.20,0.40,0.60,0.80$ and 1.00 per cent respectively. However, Tulasi was less effective. Tulasi and Pongamia, which showed the mean total per cent larval mortality ranging from $82.67 \pm 2.7$ to $96.95 \pm 3.25,65.36 \pm 4.36$ to $73,41 \pm 4.46$ and $31.10 \pm 3.38$ to $52.1 \pm 19.85$ per cent (Fig.1). The present studies showed a significance variation at Alpha $(\mathrm{P}<0.05)$ in different concentrations of Neem, Tulasi and Pongamia. Shashidar and Basalingappa (2000) who reported the mean larval mortality ranging from 55.33 to 92.23 per cent with Neem whereas, with Tulasi and Pongamia the larval mortality was ranged from 51.67 to 69.21 and 46.73 to 59.64 per cent respectively supports our findings. High larval mortality with Neem extract might have occurred because it possess insecticidal, growth regulatory and antifeedent [properties against insects (Larry, 2004). Neem seed bitter (NSB) was found to have reduced the oviposition and development of the pests (Sontakke and Dash, 1996 and Larry, 2004). The differential toxicity of these plant extracts against larvae of greater wax moth may be attributed to the presence of different toxic components in the plant 
products. The uses of these plant products are not causing any damage to the honeybee. Hence, these products can be used in control of Lepidopteron pest, greater wax moth, Galleria mellonella.

These natural plant products are more economical when compared to other chemicals. Also they would cause no health hazards to honey consumers. Beekeepers can handle these products very easily. With these advantages of plant products, particularly Neem could be suggested for controlling the wax moth infestation.

\section{REFERENCES}

Alkofahi, A., Rupporechit, J.C., Mikalajczak, K.L. and Scott, B. A. (1989). Search for new pesticides from higher plants. In: Insecticides of Plant Origin. Ed. Arnason, J.T., ACS, Washington, pp. 25-43.

Bolchi SeriniI, G. (1979). Laboratory tests on the activity of muristerone on various insects. Boll. Zoolog. Agrar. Bachicoltura, 15: 1-14.

Eischen, F.A. and Dietz, A. (1987). Growth and survival of Galleria mellonella (Lepidoptera: Pyralidae) larvae fed on diets containing honeybee collected plant resins. Ann. Entomol. Soc. Amer. 80: 74-77.

Grout, R.A. (1946). The hive and honey bee. Hamilton, Illinois, U.S.A. pp. 509

Hiremath, I.G. (1994). Isolation and identification of pesticides from selected Indian and African plants. Post-Doctoral Res. Doc., Seoul National University, South Korea. pp. 109

Khan, I.A. and Khanum, A. (1994). Fundamentals of biostatistics. Vkaaz Publications, Hyderabad, India .pp. 392431

Larry, P. Pedigo, (2004). Entomology and Pest Management" $4^{\text {th }}$ (eds.), Prentice Hall, Inc.,New Jersey, pp. 947 -950.

Shashidhar Viraktamath and S. Basalingappa (2000). Efficacy of botanicals in the management of the greater wax moth, Galleria mellonella (L.). Indian Bee J., 62(3 - 4): 41-45.

Sontakke, B.K. and Dash, A.N. (1996). Studies on the effects of insecticides and neem formulations against major pests of mustard and their safety to honeybees. Indian J. Environ. Toxicology, 6 (2): 87-88.

Whitcomb, W. Jr. (1967). Controlling the greater wax moth, A pest of honeycomb. Bull.U.S. Dept. Agric., 2217: 12. 